\title{
On the Application of WeChat Platform in the Classroom Teaching Reform Weiran Zhang ${ }^{1, ~ a, ~ L i e m i n g ~ F a n g ~}{ }^{2, b *}$ and Yajun Pan ${ }^{2, c}$ \\ ${ }^{1}$ Beijing Institute of Petrochemical Technology, Beijing, China \\ ${ }^{2}$ Shandong Youth University of Political Science, Jinan, China

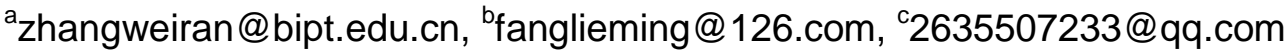 \\ ${ }^{*}$ The corresponding author
}

Keywords: Internet; WeChat public platform; Classroom teaching reform

\begin{abstract}
WeChat, a smart software based on internet, is at the advantage in today's social smart client Applications thanks to its huge amount of users. WeChat Platform- based classroom teaching methods reform can make up for the deficiencies of traditional classroom teaching mode and teaching method, and it thus contributes to the improvement of teaching quality.
\end{abstract}

\section{Introduction}

With the development of modern science and technology, the "Internet + intelligent client" based devices are changing people's way of life and their habits with unexpected results. WeChat is a smart platform which is mainly for individuals, businesses or media and it's combined with Subscription, Official Accounts and Service Accounts. Users can communicate in groups with pictures, texts and voices. WeChat is a smart device based on Internet, which has a great amount of users. The platform has the function which is not possessed by other social software, such as information push timely and accurately. Once the news is generated by the background management personnel, user who follows the WeChat Subscription can receive the news timely and accurately. Live Talk can do it while chatting and locating, students around the user can study together. The translation of foreign news has been truly realized that the user clicks on the news in foreign language and he can get an exact translation. The chat record can be collected into mail. WeChat is no longer limited to text, which is combined with picture, sound, video, animation and so on. The compatibility, convenience, real-time sharing and its timely interaction of WeChat make students' communication and learning easier. The application of WeChat public platform in classroom teaching can effectively improve students' learning enthusiasm and improve the teaching quality.

\section{The Application of Wechat Platform in the Reform of Classroom Teaching Methods}

With the development of science and technology, the modern teaching methods come into being. Teaching methods based on WeChat become more and more popular with students.

Multimedia Courseware Uploaded to Wechat Public Platform. The emergence of a large number of phubbers is also a big headache to teachers in universities. In order to solve the problem, according to their own teaching goals, teachers classify and summarize the overall teaching materials at first. After that, characters, graphics, images, sounds, animations, videos and multiple multimedia materials were integrated in the two aspects of time and space. Then teachers upload multimedia courseware to the WeChat public platform in advance so that learners obtain knowledge through the eyes, ears, hands, brains, mouths and other senses. It can make the abstract problem specific, the unimaginable problem simple. It has a significant impact to the traditional teaching method, which not only improves the students' learning efficiency, arouses interests of learning, enriches the teaching means, makes their own learning no longer boring, turns learning from passive into active, makes learning efficiency improved, but also satisfies the need of phubbers. The multimedia courseware uploaded to the WeChat can be preserved permanently, learners can look through them any time without worrying about becoming invalid.

Wechat Public Platform Based Top Qualified Courses. The top qualified course carried out in 
China is a demonstration course with top-ranking teacher teams, teaching contents, teaching methods, teaching materials as well as teaching management. The construction of advanced courses is an important part of colleges and universities' teaching quality and teaching reform project. In the university, some top qualified courses which are taught by expert and experienced professors are uploaded onto WeChat public platform. These courses are classified in sorts and updated timely in WeChat public platform. Specialized databases and links are set to facilitate the selection of learners. To coordinate the traditional teaching method and the application of modern education technology, and to integrate courses, it is necessary to construct WeChat public platform. With its convenience, interactivity and sharing, students can use the fragments of time to learn and their enthusiasm can be aroused so that their ability of studying can be promoted. Therefore, teachers and students can talk and discuss questions at any time and make full use of top qualified courses of teaching resources to improve the quality of teaching comprehensively.

Online Q\&A and Homework Correcting. The interactive network window in WeChat public platform can achieve real-time discussion between students and students, even voice discussion between teachers and students. It can achieve teachers' online answering and online homework correcting. Based on WeChat public platform, learners can get teaching courseware, teacher online Q\&A, simulation teaching and online homework correcting. With the teaching courseware and interactive discussion in WeChat public platform, learners can integrate knowledge they've learned before systematically. Students can get feedback through online test and quick correction in WeChat public platform. A special window in WeChat public platform can solve some problems in learning. Online Q\&A and homework correction in WeChat public platform have two forms. The first one is relying on some normal-problem-solving program to answer questions and correct homework with artificial intelligence. The other one is relying on teacher online Q\&A and homework correcting. With the form, a student can apply to more than one teacher to ask questions, similarly, a teacher can solve many students' questions, which improves the learning efficiency. With WeChat public platform, time and space are not a limit to students' studying any more, and teachers can solve students' problems any time. Using smart phone or pad to learn can arouse the enthusiasm of students and improve the quality of teaching.

\section{The Application of Wechat Public Platform to Case Teaching}

Wechat Based Case Teaching. By uploading the teaching-related case to WeChat public platform, students learn these cases through intelligence terminal to make full use of the rich material posted in WeChat public platform. In the teaching process, when facing some important and difficult questions, teachers can explain with related cases in order to make dull theoretical knowledge become easier to understand. In addition, case study can inspire and promote students' abilities of thinking and analyzing questions; it can make students open-minded so as to mobilize and training the students' capabilities of observing, memorizing, logic analyzing, imaging and creating, practicing and the ability of making decisions. The interesting and readable cases can effectively arouse students' enthusiasm of learning. Besides, weakness of normal textbooks, such as simple illustration and abstract reasoning process, will be made up. In WeChat, image, text, sound, animation, video and other elements can be integrated into the case teaching process. In this way, complex and abstract content will be shown flexibly, simply and vividly, and this can help students understand and digest knowledge easier. Particularly, the traditional lecturing by teacher is transformed into the initiative study and heated discussion -oriented learning of students. In the teaching process, teachers play a role of motivator and designer, encouraging students to participate in the discussion actively. It saves teaching time, expands the information, promotes study efficiency and highlights the effectiveness of teaching.

The Application of Focus Group Discussion to Wechat Public Platform. A special topic discussion (or focus group discussion) area can be set up in WeChat public platform. In this area, a learner arouses the interest of all by a problem created in class, and makes an oral report about this problem through real-time WeChat intercom function. This improves students' language skills in expressing and organizing ideas. In the heated discussion, students express true feeling freely and 
their thought collision produces the spark. They can not only realize the debate of pleasure, but also dig up knowledge, appreciating the charm of academics. On this open platform, everyone can speak up thoughts through independent thinking, and no one feels embarrassed if the answer is wrong or unacceptable to others. People get together just for learning. After a heating discussion, hearing the idea from others, learners will not only have a deeper understanding of knowledge, but also focus on the others' point of view, which trains the students' ability of thinking and learning theory, and breaks the mind-set. Set in a project discussion, students will be inspired to think positively and speak actively. This increases the interaction in teaching. Through it, students can understand the importance and difficulties appeared in course content and solve them.

The Application of Inquiry Based Teaching to Wechat Public Platform. Inquiry based teaching is also called a problem-based type of teaching. What happens is that lessons are based on what the students do not understand and that can be known through assessing them with their questions and skills. Teachers are there to accompany them in developing questions that they need to ask for them to understand the lesson well. Students are actively involved in the discovery of the problem and searching for answers, which cultivates students' ability of solving problems. In the relaxed environment of WeChat, based on teaching aims and teaching characteristics, teachers turn the difficult points into questions, and uploaded the questions to WeChat public platform. In Live Talk, with the guidance of teacher, students can discuss and learn them repeatedly. Students can discuss with teacher through the intelligent terminal, which enables students get scientific thinking by discussion and exploration and develop the abilities to solve problems. It contributes to forming scientific conceptions, arousing interests of studying and developing good personalities. Discussion through the intelligent terminal also makes students realize the objective world and the reality of science more accurately and let students study actively, explore independently to obtain more knowledge. The method is better to cultivate talents with intelligence and innovation and develop scientific exploration spirit and innovation ability.

The Application of Flipped Classroom Teaching Method to Wechat Public Platform. The flipped classroom on WeChat public platform is an innovation to the traditional teaching mode, where students have initiative and teachers play the role of guide in the whole process and also have more time to communicate with students. In this teaching mode, the existing scientific and technological achievements are applied to teaching. Teachers can upload their requirements online. Students should make some question-based PPTs, take some photos or record their problems. After that, students should upload them with some relevant materials and videos into WeChat public platform. Learners can choose their own contents to learn based on their own interests, hobbies and ability. Several students form a group to plan their learning independently with a smart phone to log onto WeChat to study. WeChat public platform based flipped classroom can save students' time to make up the lesson they may have missed. Therefore, learning time becomes more flexible and students are more involved, which facilitates students' gaining more knowledge and communicating more with their classmates. It improves students' enthusiasm and initiative. With the development of science and technology, the flipped classroom based on WeChat public platform contributes to the improvement of teaching quality.

\section{Conclusion}

WeChat public platform is now gradually involved in the classroom teaching reform. It breaks the traditional stubborn and rigid teaching mode and makes up the deficiency of the traditional teaching mode. It plays a role in supporting the reform of classroom teaching in universities and colleges. WeChat public platform must be used widely in colleges and universities as a free communication software. Universities and colleges promote the reform of classroom teaching by constructing and using the WeChat public platform. At the same time, it enriches the teaching methods and means, and also improves the teaching quality and enhances the students' learning autonomy. Therefore, WeChat public platform plays an essential role in the classroom teaching practice and reform. 


\section{Acknowledgements}

The paper is funded by the following projects: 2013 Shandong Province-level University Great Course---"Labor Economics" (course No. 2013 BK386); 2015 Training Plan to Innovation and Enterprise of National University Students (No. 201514277008)

\section{References}

[1] Wang Xunqian, Wu Junqi. Design of Mobile Learning Activities Based on the Public Platform of WeChat $[\mathrm{J}]$. Huazhong Normal University. School of Education and InformationTechnology.2016, 26 (1)

[2] Qiu, Deng Chang Xinkui, Guo Ru Mei. Application of Multimedia Technology in College Teaching [J] .Economic Research Herald. 2009 (24):234-235

[3] Dong Hongri. Present Situation, Problems and Trends of Great Course Construction [J]. Journal of Qilu Normal University.2012,27 (6) 18-19

[4] Jin Xin, Zhong Yuansheng. The Function and Construction of the Mobile Question Answering Model [J]. China Educational Technology and Equipment.2006, 12:33-35

[5] Xu Zhifang. The Application of the WeChat Based Case Teaching Method in the Teaching of Sports Physiology [J]. School Physical Education. 2015,5(23) :100-102

[6] Huang Tao. Study on Problem Research Practice [J]. Education Management. 2015

[7] Ni Lihao. Research on the Application of the Public Platform of WeChat in the Flipped Classroom [J]. Software.114-115 (4).2015, 36 